\title{
Quality of patient record keeping: an indicator of the quality of care?
}

\author{
Marieke Zegers, ${ }^{1}$ Martine C de Bruijne, ${ }^{2,3}$ Peter Spreeuwenberg, ${ }^{1}$ \\ Cordula Wagner, ${ }^{1,2,3}$ Peter P Groenewegen, ${ }^{1,4}$ Gerrit van der Wal ${ }^{2,3,5}$
}

\begin{abstract}
${ }^{1}$ NIVEL, Netherlands Institute for Health Services Research, Utrecht, The Netherlands ${ }^{2} E M G O$ Institute, VU University Medical Centre, Amsterdam, The Netherlands ${ }^{3}$ Department of Public and Occupational Health, VU University Medical Centre, Amsterdam, The Netherlands ${ }^{4}$ Utrecht University, Department of Sociology, Department of Human Geography, The Netherlands ${ }^{5}$ Netherlands Health Care Inspectorate, Utrecht, The Netherlands
\end{abstract}

Correspondence to Dr Marieke Zegers, NIVEL, Netherlands Institute for Health Services Research, PO Box 1568, 3500 BN Utrecht, The Netherlands; m.zegers@iq.umcn.nl

Accepted 25 October 2010 Published Online First 8 February 2011

\section{ABSTRACT}

Background: Patient record review of hospitalised patients is by far the most applied method to assess adverse events (AEs) in hospitals. The diligence with which information is recorded may influence the visibility of AEs. On the other hand, poor quality of the information in patient records may be a cause or a consequence of poor quality of care and may thus be associated with higher rates of AEs. The objective of this study was to assess the relation between the quality of patient records and the occurrence of AEs. Methods: In this study, 7926 hospital admissions of 21 Dutch hospitals were analysed with a structured record review method. The occurrence of AEs, the presence of patient information and the quality of the present information (completeness, readability and adequacy) were assessed. Their association was analysed using multilevel logistic regression analyses.

Results: The absence of record components was associated with lower rates of AEs, suggesting that missing record components lead to an underassessment of AEs in record-review studies. In contrast, poor quality of the information present in patient records was associated with higher rates of AEs, implying that the quality of the present patient information is a predictor of the quality of care. Conclusions: Evidence-based standards and a (electronic) format for record keeping are necessary for standardisation of recording patient information. This will improve the completeness, readability, accessibility, accuracy and exchange of patient information between healthcare providers and institutions. Better registration of patient information will benefit the quality of the healthcare process and will reduce the risk of $\mathrm{AEs}$.

\section{INTRODUCTION}

The primary aim of recording information in patient's medical records is to support the delivery of good care, clinical decisionmaking, communication between healthcare workers and continuity of care. Additionally, it is a valuable source for scientific research, quality assurance and transparency of the delivered care. Structured patient record review is by far the most widely applied method to assess the occurrence of adverse events (AEs) in hospitals and to better understand potential causes and contributory factors. ${ }^{1-13}$ However, the assessment of AEs with record review depends on the presence of data in the patient records, and therefore, there is a risk of information bias. Previous studies showed that the AE incidence rate is higher in those records with no components missing compared with records with missing components. ${ }^{9}$

Besides missing record components, the quality of the present information could also be a source of bias in record review studies. The diligence with which information is recorded may influence the visibility of AEs. Clinicians who record more data expose themselves to detection of more AEs. ${ }^{14}$ Inadequate, illegible or untraceable information may make it more difficult to detect AEs and may thus be associated with lower rates of $\mathrm{AEs}$ and could therefore bias the results of record review studies. On the other hand, poor quality of the information in patient records may be a cause or a consequence of poor quality of care and may thus be associated with higher rates of AEs.

In this article, we report on (1) the presence of patient information and the quality of the present patient information in hospital records reviewed within the Dutch Adverse Event Study; and (2) the association between the occurrence of AEs and the presence and quality of the recorded information in patient records.

\section{METHODS}

\section{Study design and setting}

We have performed a retrospective patient record review study in a random sample of 21 Dutch hospitals: four university, six tertiary 
teaching and 11 general hospitals. From each hospital, we randomly selected 200 admissions ( $>24 \mathrm{~h}$ stay) of discharged patients and 200 admissions of deceased hospital patients in 2004 (or fewer, if the total of patients who died in 2004 was lower). The study was carried out between August 2005 and October 2006. We selected admissions of 2004 to obtain a complete overview of the patient information, including a 1-year period after discharge or death of the patient. The design and methods of this study are described in detail elsewhere. ${ }^{15}$

\section{Structured review of patient records for the assessment of adverse events}

The patient record of the sampled admissions was reviewed by a trained team of 66 nurses and 55 physicians with a structured record-review process. ${ }^{15}$ The reviewers never reviewed in hospitals where they had ever been employed. In the first stage of the review process, a nurse screened the patient records by using 18 screening criteria indicating potential AEs. ${ }^{15} 16$ Patient records with one or more positive screening criteria $(n=4317)$ were reviewed by physicians in the second stage of the review process. Based on a standardised procedure, they determined the presence of AEs. An AE was defined as an unintended injury among hospitalised patients that resulted in disability, death or prolonged hospital stay, and was caused by healthcare management. ${ }^{15}$ In total, 7926 patient records were reviewed. The physicians identified one or more AEs in 663 hospital admissions. ${ }^{16}$

\section{Assessment of presence and quality of patient information}

The presence and quality (including completeness, readability and adequacy) of patient information in hospital records were judged systematically according to a format. The patient record consists of two main components: the nursing record (with the nursing progress notes, physician orders for the nurses and, if applicable, the medication list) and the medical record (with the medical progress notes, report of medical history and physical examination, discharge letter and, if applicable, the procedure reports, diagnostic imaging results and laboratory/pathology-anatomy test results).

In the first stage of the review process, the nurse reviewers assessed the presence and quality of the nursing record components of all patient records $(n=7926)$. In case the nurses found no screening criteria in the nursing record, they also reviewed the presence and quality of the medical record $(n=5171)$. In the second stage of the review process, the physician reviewers assessed the quality of the medical records that were positive for one of the screening criteria $(n=4317)$. They registered inadequacies such as 'the admission reason was not clearly described' and 'lack of clarity regarding decisions and changes in policy.'

\section{Statistical analysis}

Descriptive statistics about the presence and quality of the patient information were analysed using SPSS 14.0.

The relation between the presence and quality of patient information and the occurrence of AEs was analysed with multilevel regression analysis. Multilevel analysis was used because the data had a hierarchical nature: the adequacy of the patient information (level 1) was clustered within hospital departments (level 2), and hospital departments were clustered within hospitals (level 3). Clustering of data (no independent observations) violates a major assumption of traditional regression analysis. Multilevel models are used to analyse hierarchical structured data. ${ }^{17} 18$

The association between AEs and the presence and quality of patient information was analysed with multivariate logistic multilevel regression analysis with a random intercept at the hospital and hospital department level and with the presence of AEs (yes/no) in the patient record as a binominal outcome variable. The independent variables were the presence of record components (binomial) and the quality of the available patient information (binomial). Separate regressions were run for each type of record component. The logistic multilevel model was adjusted for several covariates: age, discharge status (deceased or discharged), admission urgency (elective, urgent or transfer from another hospital), readmission (yes/no) and hospital type (university, medical tertiary teaching or general hospitals). The contribution of the presence and quality of the record components to the occurrence of AEs was expressed with ORs with 95\% CIs. The multilevel analyses were carried out using MLwiN 2.0 software.

\section{RESULTS}

\section{Completeness of the patient records}

The nurse reviewers found that the nursing record was unavailable in $108(1 \%)$ of the patient records. The medical record was unavailable in $104(1 \%)$ and the medication list in $21 \%$ of the reviewed patient records (table 1).

Table 1 shows that the absence of record components was negatively associated with the occurrence of AEs. Fewer AEs were found in patient records with missing record components. This finding was significant for the absence of the nursing record, physician orders and laboratory/pathology-anatomy test results.

\section{Quality of the available patient information}

The nurse reviewers judged that $23 \%$ of the medical records and $10 \%$ of the nursing records were inadequate (table 2). The inadequate medical records were described as incomplete $(15 \%)$ and illegible $(8 \%)$. In 
Table 1 Percentage missing record components assessed by nurse reviewers and the association with the presence of adverse events assessed by physician reviewers

\begin{tabular}{|c|c|c|}
\hline Record components & $\begin{array}{l}\text { Missing record } \\
\text { components } \\
(\%)\end{array}$ & $\begin{array}{l}\text { OR for adverse } \\
\text { event }(95 \% \mathrm{Cl})\end{array}$ \\
\hline $\begin{array}{l}\text { Nursing record } \\
(n=7926)\end{array}$ & 1.4 & $0.3(0.1 \text { to } 0.9)^{*}$ \\
\hline Physician orders & 7.5 & $0.7(0.5 \text { to } 0.9)^{*}$ \\
\hline $\begin{array}{l}\text { Medication list } \\
\text { (if applicable) }\end{array}$ & 21.2 & 0.9 (0.8 to 1.1$)$ \\
\hline $\begin{array}{l}\text { Medical record } \\
(n=5171) \dagger\end{array}$ & 1.3 & 0.7 (0.3 to 1.5$)$ \\
\hline $\begin{array}{l}\text { Report of medical } \\
\text { history and physical } \\
\text { examination at } \\
\text { admission }\end{array}$ & 19.5 & $0.8(0.6$ to 1.2$)$ \\
\hline $\begin{array}{l}\text { Discharge letter } \\
\text { If applicable: }\end{array}$ & 13.1 & 0.9 (0.7 to 1.2$)$ \\
\hline Procedure reports & 18.0 & $0.9(0.6$ to 1.4$)$ \\
\hline $\begin{array}{l}\text { Diagnostic imaging } \\
\text { results }\end{array}$ & 27.1 & $0.9(0.7$ to 1.3$)$ \\
\hline $\begin{array}{l}\text { Laboratory/ } \\
\text { pathology-anatomy } \\
\text { reports/test results }\end{array}$ & 20.1 & $0.7(0.5 \text { to } 0.9)^{*}$ \\
\hline \multicolumn{3}{|c|}{$\begin{array}{l}\text { * } p<0.05 \text {. } \\
\text { †The nurses reviewed } 5171 \text { medical records. In case the nurses } \\
\text { found enough screening criteria in the nursing record, they did not } \\
\text { screen the whole medical record. }\end{array}$} \\
\hline
\end{tabular}

$10 \%$ of all patient records, the physician orders and in $14 \%$ the medication lists were inadequate-for example not signed by the physician, documentation unclear and disorderly, and medication list handwritten, respectively. In $12 \%$ of the patient records, the report of medical history and physical examination at admission was inadequate-for example the patient was not approachable, only a preoperative screening was done, or only a screening at the emergency department was available.

We analysed the association between the quality of the patient information and the presence of AEs in the patient record. The results in table 3 show that inadequate patient information was positively associated with AEs. More AEs were found in patient records with poor quality of patient information. This finding was significant for the quality of the discharge letter.

Table 4 shows the inadequacies per medical record component judged by the physician reviewers. They judged that, overall, $20 \%$ of medical records were inadequate or incomplete. In the 'other' category $(2 \%)$, documentation deficiencies such as information of the general practitioner, notes about allergy, and moment and circumstances of death were missing; and complications (eg, bleeding, sepsis) were not mentioned in the medical record, but only in the nursing record.

Table 4 shows that inadequacies of the medical record components judged by the physician reviewers were positively associated with the occurrence of AEs, meaning that inadequate patient information was associated with more AEs.

\section{DISCUSSION}

\section{Main results}

It was found that the absence of patient record components was associated with lower rates of AEs. Thus, missing record components lead to an underestimation of AEs in record review studies. In contrast, poor quality (completeness, readability and adequacy) of the available patient information was associated with higher rates of AEs. The quality of the recorded information in patient records seems to be a predictor of the quality of care. Better registration of patient information could

Table 2 Percentage inadequate record components assessed by nurse reviewers

\begin{tabular}{|c|c|c|c|c|}
\hline \multirow[b]{2}{*}{ Record components } & \multirow[b]{2}{*}{ Inadequate (\%) } & \multicolumn{3}{|c|}{ Content inadequate because: } \\
\hline & & Illegible (\%) & Incomplete (\%) & Other (\%) \\
\hline Nursing record $(n=7926)$ & 9.6 & NM & NM & NM \\
\hline Physician orders & 10.1 & 2.4 & 5.3 & 2.4 \\
\hline Medication list (if applicable) & 13.9 & 1.2 & 10.7 & 2.0 \\
\hline Medical record $(n=5171)^{*}$ & 23.4 & 7.7 & 14.8 & 0.9 \\
\hline $\begin{array}{l}\text { Report of medical history and physical examination } \\
\text { at admission }\end{array}$ & 12.4 & 3.9 & 7.6 & 0.9 \\
\hline $\begin{array}{l}\text { Discharge letter } \\
\text { If applicable: }\end{array}$ & 5.2 & NM & NM & NM \\
\hline Procedure reports & 2.3 & & & \\
\hline Diagnostic imaging results & 1.2 & & & \\
\hline Laboratory/pathology-anatomy reports/test results & 2.3 & NM & NM & NM \\
\hline
\end{tabular}


Table 3 Association between quality of patient information assessed by nurse reviewers and the presence of adverse events assessed by physician reviewers

\begin{tabular}{|c|c|c|}
\hline Record components & $\begin{array}{l}\text { Inadequate } \\
(\%)\end{array}$ & $\begin{array}{l}\text { OR for adverse } \\
\text { event }(95 \% \mathrm{Cl})\end{array}$ \\
\hline $\begin{array}{l}\text { Nursing record } \\
(n=7926)\end{array}$ & 9.6 & $1.1(0.9$ to 1.5$)$ \\
\hline Physician orders & 10.1 & $1.0(0.8$ to 1.4$)$ \\
\hline $\begin{array}{l}\text { Medication list } \\
\text { (if applicable) }\end{array}$ & 13.9 & 1.2 (1.0 to 1.6$)$ \\
\hline $\begin{array}{l}\text { Medical record } \\
(n=5171)\end{array}$ & 23.4 & $1.2(0.8$ to 1.6$)$ \\
\hline $\begin{array}{l}\text { Report of medical } \\
\text { history and physical } \\
\text { examination at } \\
\text { admission }\end{array}$ & 12.4 & $1.1(0.7$ to 1.6$)$ \\
\hline $\begin{array}{l}\text { Discharge letter } \\
\text { If applicable: }\end{array}$ & 5.2 & $1.5(1.1 \text { to } 2.1)^{*}$ \\
\hline Procedure reports & 2.3 & 1.4 (0.6 to 3.5$)$ \\
\hline $\begin{array}{l}\text { Diagnostic imaging } \\
\text { results }\end{array}$ & 1.2 & 1.5 (0.5 to 5.2$)$ \\
\hline $\begin{array}{l}\text { Laboratory/ } \\
\text { pathology-anatomy } \\
\text { reports/test results }\end{array}$ & 2.3 & $1.9(0.5$ to 6.4$)$ \\
\hline
\end{tabular}

contribute to better patient outcomes and safer healthcare. Missing patient record components and poor quality of the available patient information probably reflect different underlying problems in hospital: the first suggesting administrative and process issues - the unavailability of evidence-based standards and a (electronic) format for record keeping hinders healthcare providers to create a complete and accurate patient record; the second possibly reflecting the performance of healthcare providers - the diligence with which individual healthcare professionals record patient information and follow the record-keeping guidelines for registering patient information. AEs and poor quality of record keeping probably have a common cause.

\section{Methodological consideration}

A common problem of record review studies is the poor to moderate inter-rater agreement for the assessment of AEs. ${ }^{19-22}$ In this study, the inter-rater agreement for the judgement of AEs was fair for the assessment of AEs $(\kappa=0.25)$ and their preventability $(\kappa=0.40) .{ }^{16}$ Another general weakness of the retrospective record review method is hindsight bias. ${ }^{23}$ The presence of severe AEs may influence the judgement of the quality of the patient record. The association we found between the quality of the medical records judged by the physician reviewers and the occurrence of AEs could therefore be overestimated. However, the nurse reviewers are less affected by hindsight bias, since they registered the presence and quality of the patient information, but did not make judgements about the presence of AEs. The association between the presence and adequacy of the different record components judged by the nurses and the occurrence of AEs was not statistically significant for all record components, but all pointed in the same direction as the associations based on physician judgements. Future research should confirm the findings of this study and the influence of hindsight bias. Hindsight

Table 4 Inadequacies of the medical record assessed by physician reviewers* $(n=4317)$ and the association with the occurrence of adverse events

\begin{tabular}{|c|c|c|}
\hline & $\begin{array}{l}\text { Frequency } \\
(\%)\end{array}$ & $\begin{array}{l}\text { OR for adverse } \\
\text { event }(95 \% \mathrm{Cl})\end{array}$ \\
\hline Medical record inadequate or incomplete & 20.0 & $1.5(1.3$ to 1.9$) \dagger$ \\
\hline $\begin{array}{l}\text { Report of past medical history and physical examination at admission inadequate } \\
\text { or incomplete }\end{array}$ & 12.4 & $1.3(1.0$ to 1.7$) \dagger$ \\
\hline $\begin{array}{l}\text { Other reports not available or incomplete (eg, operation/procedure report, } \\
\text { diagnostic imaging results, reanimation report or autopsy report) }\end{array}$ & 11.0 & $1.7(1.3$ to 2.1$) \dagger$ \\
\hline Discharge letter not available & 10.7 & $1.0(0.7$ to 1.3$)$ \\
\hline Lack of clarity regarding decisions and changes in policy & 8.3 & $2.0(1.5$ to 2.6$) \dagger$ \\
\hline Discharge summary not adequate, because*: & 7.9 & $1.9(1.5$ to 2.4$) \dagger$ \\
\hline Discharged diagnose is missing & 2.8 & $1.9(1.2$ to 3.0$) \dagger$ \\
\hline Prognosis is missing & 2.1 & $1.5(0.9$ to 2.7$)$ \\
\hline Treatment policy is missing & 3.5 & $1.7(1.1$ to 1.5$) \dagger$ \\
\hline Agreement of supervisor is missing & 0.9 & $1.2(0.5$ to 2.8$)$ \\
\hline Notes on procedure related to adverse event inadequate & 6.9 & $3.2(2.5$ to 4.3$) \dagger$ \\
\hline Lack of clarity regarding who was responsible for decisions and changes in policy & 5.8 & $2.5(1.8$ to 3.4$) \dagger$ \\
\hline Lack of clarity when changes in policy were made & 5.5 & $1.7(1.2$ to 2.4$) \dagger$ \\
\hline Admission reason not clearly described & 4.0 & $1.3(0.9$ to 2.0$)$ \\
\hline Other & 2.2 & $1.5(0.9$ to 2.6$)$ \\
\hline
\end{tabular}

*Physicians could register more options per record.

$t p<0.05$. 
bias could be avoided by independent assessment of the occurrence of AEs and the presence and quality of patient information.

\section{Implications for practice to enhance patient safety}

An improvement in the registration of patient information and (inter)national standardisation of the design of the patient record are desirable to enhance the quality, accessibility and exchange of patient information between healthcare providers, hospital departments and healthcare institutions. Unequivocal, efficient and accessible record-keeping guidelines for the documentation of patient information may lead to better communication between healthcare providers and will contribute to better patient outcomes and safer healthcare. These (inter)national guidelines should be incorporated within the training of care providers and could be used for accreditation and visitation of hospitals. They could be based on the evidence-based recordkeeping standards for inpatients developed by the British Royal College of Physicians. ${ }^{24}$ Preferable is an integrated patient record for all healthcare workers and keeping all records relating to a patient in a single patient record rather than divided between several hospital departments or sites of care. ${ }^{25}$

Recording information is both burdensome and timeconsuming. The implementation of an electronic patient record hospital-wide will contribute to the standardisation, ease of recording, completeness, accessibility, availability and exchange of patient information. ${ }^{26}$ Probably, electronic patient records are more complete than handwritten records because of the possibility of integrating multiple data sources-for example, laboratory test results and medication data. However, the data in the electronic medical record are entered by humans and therefore prone to error and bias. ${ }^{27}$ Implementation of an electronic patient record will have the desired effect if the recording of patient information is standardised. "A mess computerised is a computerised mess. ${ }^{24}$

Acknowledgements We thank everyone who contributed to the study: the nurses and physicians who reviewed the patient records; the researchers for the coordination of the data collection; and the 21 participating hospitals and their staff who facilitated the patient records.

Funding The Dutch Patient Safety Research Program has been initiated by the Dutch Society of Medical Specialists (in Dutch: Orde van Medisch Specialisten) with financial support from the Ministry of Health, Welfare and Sport. The Program is carried out by EMGO Institute/VU University Medical Centre and NIVEL.

\section{Competing interests None.}

Provenance and peer review Not commissioned; externally peer reviewed.

\section{REFERENCES}

1. Weingart SN, Wilson RM, Gibberd RW, et al. Epidemiology of medical error. BMJ 2000;320:774-7
2. Vincent C, Neale G, Woloshynowych M. Adverse events in British hospitals: preliminary retrospective record review. BMJ 2001;322:517-19.

3. Brennan TA, Localio AR, Leape LL, et al. Identification of adverse events occurring during hospitalization. A cross-sectional study of litigation, quality assurance, and medical records at two teaching hospitals. Ann Intern Med 1990;112:221-6.

4. Baker GR, Norton PG, Flintoft V, et al. The Canadian Adverse Events Study: the incidence of adverse events among hospital patients in Canada. CMAJ 2004;170:1678-86.

5. Thomas EJ, Studdert DM, Burstin HR, et al. Incidence and types of adverse events and negligent care in Utah and Colorado. Med Care 2000;38:261-71.

6. Brennan TA, Leape LL, Laird NM, et al. Incidence of adverse events and negligence in hospitalized patients. Results of the Harvard Medical Practice Study I. N Engl J Med 1991;324:370-6.

7. Soop M, Fryksmark U, Köster M, et al. The incidence of adverse events in Swedish hospitals: a retrospective medical record review study. Int J Qual Health Care 2009;4:285-91.

8. Davis P, Lay-Yee R, Briant R, et al. Adverse events in New Zealand public hospitals I: occurrence and impact. NZ Med J 2002;115: U271.

9. Wilson RM, Runciman WB, Gibberd RW, et al. The Quality in Australian Health Care Study. Med J Aust 1995;163:458-71.

10. Michel P, Quenon JL, de Sarasqueta AM, et al. Comparison of three methods for estimating rates of adverse events and rates of preventable adverse events in acute care hospitals. $B M J$ 2004;328:199.

11. Schioler T, Lipczak H, Pedersen BL, et al. Incidence of adverse events in hospitals. A retrospective study of medical records (in Danish). Ugeskr Laeger 2001;163:5370-8.

12. Aranaz-Andrés JM, Aibar-Remón $\mathrm{C}$, Vitaller- Murillo $\mathrm{J}$, et al. Incidence of adverse events related to health care in Spain: results of the Spanish National Study of Adverse Events. J Epidemiol Community Health 2008;12:1022-9.

13. Smits M, Zegers M, Groenewegen PP, et al. Exploring the causes of adverse events in hospitals and potential prevention strategies. Qual Saf Health Care 2010:19:1-7.

14. Lilford RJ, Mohammed MA, Braunholtz D, et al. The measurement of active errors: methodological issues. Qual Saf Health Care 2003;12 (Suppl 2):ii8-12.

15. Zegers M, Bruijne MC, Wagner $C$, et al. Design of a retrospective patient record study on the occurrence of adverse events among patients in Dutch hospitals. BMC Health Serv Res 2007;7:27.

16. Zegers M, Bruijne MC, Wagner C, et al. Adverse events and potentially preventable deaths in Dutch hospitals. Results of a retrospective patient record review study. Qual Saf Health Care 2009:18:297-302.

17. Twisk JWR. Applied Multilevel Analysis: A Practical Guide. Cambridge: Cambridge University Press, 2006.

18. Snijders TAB, Bosker RJ. Multilevel Analysis; an Introduction to Basic and Advanced Multilevel Modelling. London: Sage Publications, 1999.

19. Thomas EJ, Lipsitz SR, Studdert DM, et al. The reliability of medical record review for estimating adverse event rates. Ann Intern Med 2002;136:812-16.

20. Brennan TA, Localio RJ, Laird NL. Reliability and validity of judgments concerning adverse events suffered by hospitalized patients. Med Care 1989;27:1148-58.

21. Localio AR, Weaver SL, Landis JR, et al. Identifying adverse events caused by medical care: degree of physician agreement in a retrospective chart review. Ann Intern Med 1996;125:457-64.

22. Lilford R, Edwards A, Girling A, et al. Inter-rater reliability of case-note audit: a systematic review. J Health Serv Res Policy 2007:12:173-80

23. Fischhoff $B$. Hindsight not equal to foresight: the effect of outcome knowledge on judgment under uncertainty. J Exp Psychol: Human Percept Perform 1975;1:288-99.

24. Royal College of Physicians. Draft RCP record keeping standards -inpatients (version 5) 2003. http://hiu.rcplondon.ac.uk/ clinicalstandards/recordsstandards/rec_standards.pdf (accessed 12 Aug 2008).

25. Wilson RM. Reviewing case record review. More public discussion is needed on the role and content of the case record. Qual Saf Health Care 2003;12:402-3.

26. Amarasingham $\mathrm{R}$, Plantinga $\mathrm{L}$, Diener-West $\mathrm{M}$, et al. Clinical information technologies and inpatient outcomes: a multiple hospital study. Arch Intern Med 2009;169:108-14.

27. Thomas EJ, Petersen LA. Measuring errors and adverse events in health care. J Gen Intern Med 2003;18:61-7. 


\section{Quality of patient record keeping: an indicator of the quality of care?}

Marieke Zegers, Martine C de Bruijne, Peter Spreeuwenberg, et al.

BMJ Qual Saf 2011 20: 314-318 originally published online February 8, 2011

doi: $10.1136 /$ bmjqs.2009.038976

Updated information and services can be found at:

http://qualitysafety.bmj.com/content/20/4/314.full.html

These include:

References This article cites 24 articles, 13 of which can be accessed free at: http://qualitysafety.bmj.com/content/20/4/314.full.html\#ref-list-1

Email alerting Receive free email alerts when new articles cite this article. Sign up in service the box at the top right corner of the online article.

Notes

To request permissions go to:

http://group.bmj.com/group/rights-licensing/permissions

To order reprints go to:

http://journals.bmj.com/cgi/reprintform

To subscribe to BMJ go to:

http://group.bmj.com/subscribe/ 